\title{
Intermédialités
}

Histoire et théorie des arts, des lettres et des techniques

Intermediality

History and Theory of the Arts, Literature and Technologies

\section{Programming and Reprogramming Artworks: A Case of Painting and Practicing Conceptual and Media Art by Other Means}

\section{David Tomas}

Numéro 13, printemps 2009

Programmer

Programming

URI : https://id.erudit.org/iderudit/044042ar

DOI : https://doi.org/10.7202/044042ar

Aller au sommaire du numéro

Éditeur(s)

Centre de recherche sur l'intermédialité

ISSN

1705-8546 (imprimé)

1920-3136 (numérique)

Découvrir la revue

Citer cet article

Tomas, D. (2009). Programming and Reprogramming Artworks: A Case of Painting and Practicing Conceptual and Media Art by Other Means.

Intermédialités / Intermediality, (13), 89-113. https://doi.org/10.7202/044042ar
Résumé de l'article

" Programming and Reprogramming Artworks » développe une réflexion sur la pratique « aiguillographique » de Rosika Desnoyers et, plus spécifiquement, son rapport au concept de programmation et à l'automatisation du travail manuel. L'article explore, dans un premier temps, la manière par laquelle l'artiste investit une histoire des erreurs qui s'est tracée en marge du programme automatisé inhérent à la production de broderies de style Berlin. Dans un deuxième temps, l'étude de la pratique de Desnoyers est approfondie et mise en relation avec l'art conceptuel et le développement de la " peinture par d'autres moyens". 


\title{
Programming and Reprogramming Artworks: A Case of Painting and Practicing Conceptual and Media Art by Other Means
}

\author{
David Tomas
}

(2.) Rational judgements repeat rational judgements.

(3.) Illogical judgements lead to new experience.

(5.) Irrational thoughts should be followed absolutely and logically.

Sol LeWitt, "Sentences on Conceptual Art."

The phrase "programming language" is most often associated with computing technologies where it refers, generally, to an artificial language that is used to create a program through which a set of instructions is communicated to the computer so that it is able to execute a series of well-defined tasks. ${ }^{2}$ Another way to describe this "is to take some kind of problem statement and put it into a form which can be understood by a computer and hence solved." 3 These non-technical

1. Sol LeWitt, "Sentences on Conceptual Art," Art ङ Language, vol. 1, n 1, May 1969 , p. 11.

2. See for example the definition of programming language in en.wikipedia.org/wiki/ Programming_language (last access March 14, 2010). For an in-depth technical discussion of programming languages and their characteristics, see Jean E. Sammet, Programming Languages: History and Fundamentals, Englewood Cliffs, Prentice-Hall, 1969.

3. Ibid., p. 729-730. For a history of post-Second World War computer programming languages see Richard L. Wexelblat, History of Programming Languages, New York, London and Toronto, Academic Press, 1981. For another interview-based overview of the development of various kinds of programs, see Susan M. Lammers, Programmers at Work: Interviews with 19 Programmers Who Shaped the Computer Industry, Redmond, Tempus Books of Microsoft Press, 1989. 
definitions articulate the major etymological roots of the word "program" (proclamation, edict, or a public written notice) through a series of transformations ("problem statement" in a natural language (such as English), a machine language, and as expressed through the execution of the desired task) into and out of a machine world. ${ }^{4}$ In this paper I will use the concept of a "programming language," in these broad more abstract senses, to guide my discussion of a contemporary form of Berlin work style of canvas work, a subcategory of embroidery, produced by the Montreal-based artist Rosika Desnoyers. There are specific reasons why I have chosen to limit myself to a common and perhaps "undisciplined" use of the concept of programming language (as opposed to pursuing a more technical or academic discussion of programming languages) which has to do with the particularity of Desnoyers' practice and the unusual way that it is positioned, in an interdisciplinary/intermedial fashion, at the intersection of the histories of embroidery, early methods of programming and computing, and contemporary art. The adoption of a narrow definition of programming language or an excessively specialized and technical discussion of its characteristics were unnecessary given the kinds of relationships that I explored and that I will be describing in this article.

In the following pages, I will situate Desnoyers' canvas work in relation to the historical development of Berlin work embroidery. I will begin to situate her work by describing Berlin work charts, their grid based logic, their language, program of work, and the automation of creativity that they promoted. I will then describe how Desnoyers' canvas work extends and transforms Berlin work's program, in terms of its own program of work which is based on mapping errors in an original reference work. I will go on to demonstrate how Desnoyers' practice is situated in relation to post-196os contemporary art, in particular Sol LeWitt's 1966 conceptual art program as presented in his "Paragraphs on Conceptual Art" (1967) and "Sentences on Conceptual Art" (1969). I will conclude my discussion with a summary of the idea of painting and practicing conceptual art by other means, the role of programming in this approach, and its impact on notions of media art.

4. See, for example, the following etymological definition of program: "1633, "public notice,' from L. L. programma 'proclamation, edict,' from Gk. programma (gen. programmatos) 'a written public notice' from stem of prographein 'to write publicly', from pro'forth' + 'graphein' to write."' www.etymonline.com/index.php?term=program (last access March 14, 2010). 


\section{BERLIN WORK AND ITS PROGRAM OF WORK}

Berlin work was first developed in Germany in the early $19^{\text {th }}$ century. It was generally practiced by amateur women embroiderers and pursued as a leisure activity in a domestic context. By mid century it was popular in England and America where it flourished till the last quarter of the century when it fell out of favour under the pressures of the Art and Crafts and Pre-Raphaelite Movements with their promotion of anti-industrial and anti-commercial craft-based forms of needlework practices. However, notwithstanding its decline, Berlin work continues to be practiced today as part of the tradition of canvas work embroidery. ${ }^{5}$

Berlin work is a form of counted-thread embroidery (or mesh-based canvas work) produced in different colours and hues of wool, the choice and placement of which were originally determined, in the early $19^{\text {th }}$ century, by mass-produced black and white grid-based patterns or charts that were initially hand coloured and subsequently mechanically reproduced in colour. Its specificity as a craft-based practice was to be found in the grid systems of these mass-produced coloured charts. The charts differed from earlier forms whose printed outlines allowed for the unrestricted use of a variety of colours, shading and stitching styles. In contrast, Berlin charts automated the process of producing embroideries by restricting (or guiding) the choices-colour, hue, and the exact placement of each stitch-that an embroiderer had to make in order to complete the pattern.

Berlin work charts were allied to basic methods of mass production in two ways. First, through a division of craft labour based on four stages of production: the creation of a master copy of an original pattern or picture on point paper (a highly paid and specialized activity); the production of a copper plate that was ruled in squares of corresponding size with symbols representing the colours in the master copy (again a specialized activity); the printing of the copies; and finally the hand painting of the coloured squares (according to the information registered in the symbols) in each of the prints (a piecemeal, low paid activity involving women, men and sometimes children). ${ }^{6}$ Second, it was associated with methods of mass production through its automation of a significant portion of the embroiderer's creative activity.

5. For a historical discussion of Berlin work, see Joan Edwards, The First of Joan Edwards' Small Books on the History of Embroidery: Berlin Work, Dorking, Bayford Books, 1980.

6. Ibid., np. 
One of the most significant characteristics of Berlin work was their use of what was known as point or quadrille paper, a system of printed square grids (resembling modern graph paper) that corresponded to the grid or mesh-based system of canvas. This system allowed for the exact reproduction of a picture through a displacement of a stitch/colour's position from the pattern to the canvas. Inasmuch as the grid system's structure and area was aligned with the canvas weave's structure and area, the grid system allowed for a method of copying which guaranteed a potentially meticulous reproduction. Since the coloured wool could often be purchased with the pattern, Berlin work functioned as a form of "painting by numbers" in the case of the reproduction of an existing painting." The use of a colour coded point paper system replaced earlier patterns that were produced as outlines or on grids of coded squares whose symbols corresponded to colours that then had to be individually translated by the embroiderer during the course of producing an embroidery. ${ }^{8}$ Although they functioned in a similar way to the grid system of information transfer used in the production of a painting, at least since the Renaissance, the density, or fine resolution of Berlin work's grid system (the largest of which could contain up to half a million or more squares) places it midway between a painter's use of this kind of information transfer system and a grid system's pixel-based use in the case of the digital image. ${ }^{9}$ If the function and mechanical/electronic organization of the latter is fundamentally different, then the grid-based logic upon which each system is based suggests that they share a common foundation.

Under the new regime, an embroiderer was able to methodically transfer visual information related to a stitch's precise position and its colour by counting horizontal and vertical lines on the pattern and then visually transferring each

7. Although the actual manufacture of paint by number kits for adult use only appeared in the late 1940s in the United States, the logical basis of this type of automated practice of copying can certainly be traced to Berlin work's point paper system of printed square grids.

8. Printed pattern books existed in the $16^{\text {th }}$ century and hand-coloured charts based on a grid system were used by weavers in the second half of the $18^{\text {th }}$ century. Ibid., np.

9. The figure of half a million squares is noted as an estimate in Edwards, 1980. For an extended discussion of the pixel and its history see Richard F. Lyon, "A Brief History of "Pixel," www.foveon.com/files/ABriefHistoryofPixel2.pdf (last access March 14, 2010), and Alvy Ray Smith, "A Pixel is Not a Little Square, A Pixel is Not a Little Square, A Pixel is Not a Little Square! (And a Voxel is Not a Little Cube)," Technical Memo 6, July 17, 1995, (with an addition on November 11, 1996), www.alvyray.com/memos/6_pixel.pdf (last access March 29, 2010). 
square's position onto a canvas through a corresponding process of calculation. Each element of information could therefore be placed in its correct position. Eventually, the grid patterns were printed directly on the canvas thus eliminating the laborious stage of information transfer between pattern and canvas. While there was always the possibility of information loss, as a consequence of the grid resolution's neutralization by the canvas' texture, the patterns can be understood to have embodied a de facto program of work. This program "automated" important components of the embroiderer's creative decision-making capacity. Even if an embroiderer was free to substitute colours and stitches for the encoded ones, the program was always there to function as a substitute of independent thought when necessary or desired.

By engaging with this proto-automatic form of needlepoint production the embroiderer lost effective control over a major portion of the creative process of producing a picture since the choice of subject, composition and colour were effectively built into the system. In exchange, the Berlin work system allowed its adherents to produce complex patterns without engaging in these three demanding processes of picture making activity. In addition, devotees were implicated, if only unconsciously, in one of the most momentous processes of social transformation and re-adaptation initiated under the auspices of the industrial revolution (the automation of manually-based labour practices); and they were subject to one of its more subtle areas of infiltration: the gradual automation of manual labour practices in the case of highly specialized picture making activities. This is apparent in the division of labour underlying the production of the Berlin chart and in its integrated program of reducing the knowledge, skill, and labour time associated with the production of embroideries.

Various approaches to the automation of creativity in the early $19^{\text {th }}$ century triggered a revolutionary process of democratization in picture making practices that has been mainly associated with the invention and development of photographic processes of pictorial reproduction. ${ }^{10}$ The introduction of photography in 1839 circumvented the high degree of skill and talent as well as the

10. One can compare the impact of the grid system's automation of canvas work, especially in its Berlin work form, in the case of embroidery to that of photography's impact on drawing and painting. In the latter case, the automation of picture making was celebrated, in particular, in Daguerre's manual of 1839 in terms of the automation of skill-based draughtsmanship and it was further celebrated as a democratization and popularization of picture making activity. See, for example, Louis-Jacques-Mandé Daguerre, An Historical and Descriptive Account of the Various Processes of the Daguerreotype and the Diorama [1839], Beaumont Newhall (ed.), facsimile edition, New York, Winter House Ltd., 1971, 
extensive periods of time that were needed to produce pictorial reproductions including drawings and paintings. In both cases, an expansion in the numbers of people implicated in picture making activity was achieved through a deskilling of specialized labour's intensive forms of manual work. Both were based on the same principle of the copy that operated as the underlying logic of other industrial methods of mass-production. ${ }^{11}$ However, during its heyday, Berlin work effectively transformed embroidery, as practiced by women in domestic environments, from a predominantly "aristocratic" pastime to one associated with the middle and upper middle classes through the medium of its mass-produced patterns.

The emergence of the Berlin work system of pictorial reproduction in the first decade of the $19^{\text {th }}$ century brings to mind Jacquard's programmable loom, a semi-automatic mechanical system of textile weaving which was also developed in the first decade of the century. ${ }^{12}$ The particularity of Jacquard's system resided in its novel use of punch cards to control the sequence of operations that a loom performed in order to change the pattern of a textile design during a continuous process of weaving threads into a final textile product. ${ }^{13}$ The pattern was encoded by way of a series of holes punched into a pasteboard card. The holes were organized into rows and columns with the presence or absence of a hole determining the actions of the loom. Complex patterns were produced by linking long sequences of cards together into an extensive "program" of weaving. This form of program bears a close structural resemblance to a computer program since the holes in the pasteboard cards function as the program's human/

and William Henry Fox Talbot, The Pencil of Nature, a Facsimile of the 1844-1846 Edition with a New Introduction by Beaumont Newhall, New York, Da Capo Press, 1969.

11. On the principle of the copy in the $19^{\text {th }}$ century, see Charles Babbage, The Economy of Machinery and Manufactures, Chapter XI, reprinted in Martin Campbell-Kelly (ed.), The Works of Charles Babbage, London, William Pickering, vol. 8, 1989, p. 49-78.

12. The Jacquard loom was initially invented in France by Joseph Marie Charles (1752-1834) in 1801, slightly earlier then the Berlin work system which was introduced in 1810 by a Madame Wittich of Berlin, specifically with the amateur embroiderer in mind. On the origins of Berlin work, see Edwards, 1980, np. See also Therle Hughes, English Domestic Needlework, 1660-1860, London, Abbey Fine Arts, 1961, p. 234.

13. Jacquard's use of pasteboard punch cards improved on the earlier perforated paper tape methods of control invented by Basile Bouchon in 1725, Jean-Baptiste Falcon's improvements of 1728 which consisted of introducing chains of punch cards, and Jacques Vaucanson's proposals for methods of loom automation. For a brief discussion of these filiations see Walter English, The Textile Industry: an Account of the Early Inventions of Spinning, Weaving, and Knitting Machines, London and Harlow, Longmans, Green and Co., 1969, p. 108-111. 
machine interface because of the way that they serve to translate/communicate "instructions" to the machine on its own terms. However, the production of the pasteboard programs was based on the transfer of spatial information from a large-scale design template produced on paper (a picture of the final product whose area was divided into a grid-system) to a sequence of pasteboards via a special frame; thus suggesting that a grid system was also fundamental to the development of these kinds of programs. ${ }^{14}$

The use of programs of different types that were based on similar kinds of grid system in weaving demonstrate how grids were used in different ways to introduce and promote processes of automation of different levels of complexity in picture making processes that had previously implicated and promoted specialized craft-based definitions of human creativity. They illustrate how simple graphic systems could function as strategic pathways of automation in manual picture making practices that had a minimum of machine dependence. These programs point to the emergence of a new form of labourer-the programmerand this person's position as information broker in picture making practices. Moreover, they demonstrate how these new programmers functioned as translators between different types and functions of visual information. Finally, they also reveal how the function of the programmer was "built into" the production of the Berlin charts and the Jacquard pasteboards.

The perspective machines, camera obscuras, and the grid system of information transfer that were used in painting and drawing since the Renaissance also promoted a particular "program of work." This program consisted of systemically organizing two-dimensional space, and any pictorial events that took place in it, according to a system of geometric perspective. The program it proposed was designed to naturalize space and the contents that served to define its characteristics in a way that could ensure a high degree of coherence between different works of art and a model of reality that was based on the theories and optics of human vision. However, its use was confined to specialists-skilled draughtsmen-whose training remained closely tied to craft practices, innate talent, and a minimum of technical expertise. In this sense, these earlier forms of program were resistant to the inroads of the more democratic forms of automated creativity that began to appear in the early $19^{\text {th }}$ century, perhaps because their use still depended on basic skills of draughtsmanship. Even a copy produced with

14. For a description of this process see James Essinger, Jacquard's Web: How a Hand-Loom Led to the Birth of the Information Age, Oxford, Oxford University Press, 2004, p. 281-282, and English, 1969, p. 110-112. 
the help of a camera obscura was based on basic drawing skills, not to mention the cost of the instrument itself. Moreover, the programs that were encoded in the perspective machines were integrated into their basic physical design which, far from being simple (like a Berlin work's grid pattern), resembled closely, in their forms and use, scientific instrumentation whose conceptual and practical logics were directly rooted in specialized scientific theories and mathematics. ${ }^{15}$ Here one might point out that the new forms of grid-based programs promoted a simpler, mass-produced, and more democratic model of creativity. One must not forget that it was only with the Kodak camera's appearance in 1888 that picture making became a distinct possibility for most, if not all, the social strata of society. However, it is also important to realize that these different programs for the mechanization of creativity promoted one basic concept and model of production based on automation; and that automation created complex and often insidious conditions of dependence. ${ }^{16}$

Andrew Ure defined the word "automatic" in connection with "such economic arts as are carried on by self-acting machinery" in A Dictionary of Arts, Manufactures, and Mines, his authoritative, state of the art compendium on the manufacturing processes of the Industrial Revolution. He noted in the entry on this word that “... 'manufacture,' in its etymological sense, means any system, or objects of industry, executed by the hands; but in the vicissitude of language, it has now come to signify every extensive product of art which is made by machinery, with little or no aid of the human hand, so the most perfect manufacture is that which dispenses entirely with manual labour." Ure captured, in this one sentence, the essence of the word "manufacture" as well as the trend and the final objective of its machine-based evolution. He continued:

It is in our modern cotton and flax mills that automatic operations are displayed to most advantage; for there the elemental powers have been made to animate millions of complex organs, infusing into forms of wood, iron, and brass, an intelligent agency. And as the philosophy of the fine arts, poetry, painting, and music, may be

15. For an example of the complex physical and historical status of the camera lucida's optical element and its relationship to head-mounted displays, see David Tomas, Beyond the Image Machine: a History of Visual Technologies, London and New York, Continuum, 2004. p. 105-135.

16. The radical nature of the democratic model promoted by the Kodak and the special type of corporate dependency it cultivated is captured in the Eastman Dry Plate \& Film Company's advertising slogan of 1888: "You press the button - we do the rest." 
best studied in their individual master-pieces, so may the philosophy of manufactures in these its noblest creations. ${ }^{17}$

Ure's comparative observations highlight one of the most significant innovations to have determined the development of modern industrial society: the recoding of human intelligence and manually-based activity into machine forms that both embody and operate on the basis of "intelligent agency." But he also failed to detect the significance of a similar if more subtle transformation in picture making practices. For in this definition, Ure still seems to define visual art in terms of individual masterpieces. However, if he failed to expose the operations of mechanically-based intelligent agency in picture making practices, Ure nevertheless correctly identified the keyword and the key process for both the new regime of intelligent machine-based agency and for its mass-produced picture making programs. This word is "automatic."

Ure went on to make the following point about the processes of automation he was surveying:

The constant aim and effect of these automatic improvements in the arts are philanthropic, as they tend to relieve the workmen either from the niceties of adjustment, which exhaust his mind and fatigue his eyes, or from painful repetition of effort, which distort and wear out his frame. ${ }^{18}$

Although these comments were based on the new forms of steam-powered machinery that were being used in the various textile mills of England, as a consequence of Richard Arkwright's innovations, his dictionary does contain another item that focuses specifically on embroidery and its mechanical automation.

Ure's entry for "Embroidering Machine” begins with the following statement:

This art has been till of late merely a handicraft employment, cultivated on account of its elegance by ladies of rank. But a few years ago M. Heilmann of Mulhause invented a machine of a most ingenious kind, which enables a female to embroider any design with 80 or 140 needles as accurately and expeditiously as she formerly could do with one. ${ }^{19}$

The distinction between the terms "handicraft employment," "cultivated" in the case of embroidery by "ladies of rank," and the multiplication of mass

17. Dr. Andrew Ure, A Dictionary of Arts, Manufactures and Mines, London, Longman, Orme, Brown, Green and Longmans, 1839. p. 76.

18. Ibid.

19. Ibid., p. 429. 
produced embroideries by a machine assisted embroiderer who could work "as accurately and expeditiously as she formerly could do with one [needle]," captures the essence of the application of processes of automation to work practices involving lengthy, but irregular, periods of self-regulating forms of repetitive activity. Automation provided a means of promoting continuous work practices that were independent of the human body's physical and biological limits. Automatic and semi-automatic machines augmented or replaced human labour, thereby circumventing the limits of a worker's body and his/her ability to concentrate on a given task over long periods of time. The capacity for production was therefore multiplied temporally (capacity for continuous non-stop work) and spatially (ability to simultaneously produce multiple versions of the same product).

Berlin work is another example of automation that, however, is not machinebased in the same way that a steam powered loom is, and neither did it take place in a concentrated machine-based environment like a factory. It was essentially a domestic practice. Therefore, it was closely related to traditional picture making practices, especially in their domestic, semi-professional or amateur forms. However, in the case of Berlin work, the reduction of continuous areas of colour to discrete squares laid out in a grid pattern points to another method of mechanizing the production of textile patterns based on a different example of how a program can be conceived. This type of program is less abstract than the punch card's binary presence/absence system, and, when the system is overlaid on an analogue image, like a painting, it produces discrete areas of colour that are defined by and correspond to the pattern of a canvas weave. The grid system encodes in a very basic and elementary fashion a program of work-of reproduction-that is displayed in a succinct fashion. Unlike the punch card with its sets of discrete instructions (which were designed to "communicate, with a machine"), the grid directly dissects an analogue image into discrete packages of information whose precise position on another surface can be determined through a shifting set of horizontal/vertical coordinates. As in the case of its use in the production of punch cards for a Jacquard loom, the grid system seems to prepare the way for another level of abstraction that is encoded in the punch card's binary logic (hole/no hole).$^{20}$ However, in the case of Berlin work, there is no machine to communicate with. Instead, it is a human agent that is the target of this program, and its widespread success can be attributed to the low level of its abstraction.

20. See Essinger, 2004, p. 277-279 for a description of the punch card's function. 
It is interesting to note that a similar model of discrete packages of information exists today in the case of the electronic production and reproduction of pictures: the digital image. In this case, the digital image's resolution is much finer and its electronic pixel-based matrix is much more complex in structure when compared to the grid system of a Berlin work pattern. However, both these processes essentially perform the same function of reducing a picture to discrete elements of one form or another, of accurately transferring information through space and time and with the objective of reconstructing the picture.

The historical correspondences between Berlin work and other types of a grid system are revealing when considered in the context of the $19^{\text {th }}$ century automation of creativity. For example, the Jacquard punch card was based on specialization (at the level of the production and use of the punch cards, as well as in regard to the construction and operation of the looms). In contrast, the Berlin work pattern represented-although the product of an equally refined division of labour and similar pattern making skills - a basic and non-specialized solution to the automation of creativity since its logic and program of work could be understood and used by anyone.

On the one hand, Berlin work's grid system had a major impact on the categories and demographics of embroidery practices as expressed through the shifting boundaries of the amateur and professional control over subject matter, media and skill. On the other hand, this essentially two-dimensional visual form of programming the composition and the colours of a work in relation to subject matter was very different in form, if not in the objectives of automation when compared to the use of various abstract forms of notation or language-like systems that are now associated with conventional programming. This difference pivots on the nature and intelligibility of the code(s) used for constructing the program. Contemporary codes are specialized languages that require a level of training while the code in the case of Berlin work is geometric and serial in form (the training being confined to the "mastery" of a range of embroidery stitching necessary for its correct execution). ${ }^{21}$

If one applies the standard definition of a machine program to a Berlin work pattern, then one is confronted with the problem of isolating the three stages that are implicated in the program's execution, where each stage is defined by the program's particularity. The first is represented by a series of instructions and

21. For an overview of the various practices of computer programming see Lammers, 1989. For an overview of the recent history and evolution of computer programs see Wexelblat, 1981. 
its specific language. The second is the machine language in which the original instructions are encoded so as to be understood by the machine. The third is defined by the tasks that are executed by the machine (the success of which can be measured against the original objectives of the first set of instructions). Berlin work patterns exhibit a similar tripartite organization from the viewpoint of their execution: instructions (what is to be done) in an original language (here one can refer to the original painting, design, or another "original" two-dimensional pictorial source), the "machine" language (the grid system, whose content is determined by the original source), and the tasks to be executed by the machine itself. This consists of the actions-based on an analysis of grid system's picture elements-that the embroiderer undertakes in the capacity of a self-regulating machine (inasmuch as her/his actions are governed by the information contained in the grid system) to successfully produce an embroidery. ${ }^{22}$

The relationship between the pattern, the embroiderer and the embroidery can also be understood in terms of the activities of a "human computer" (in the sense of an individual who performs calculations). ${ }^{23}$ For, in order to create a canvas work, the embroiderer has to calculate the position of each stitch through a transfer of information that is based on counting and simple numerical calculations. Finally, it must be noted that the most important characteristic of the Berlin work system of reproduction is the fact that it is based on a very simple and easily understood geometric shape-the square-whose size is predetermined and fixed, and whose form is then multiplied horizontally and vertically. This form of program is not coded in any natural or formal/machine-based language. Moreover, if the "operator" of the program functions (calculates) in terms of composition and colour (two of the basic areas of creativity in traditional picture making practices), then the question of "input" (as currently defined in computing) is reduced to and governed by the operator's choice of subject matter and, perhaps, the form of stitch to be used in constructing the picture.

These historical relationships and correspondences are more important than they might appear. When they are imported into the present in the form of a practice that is based on canvas work, grid systems, and simple numerical

22. Note that there is an interesting correspondence to be made between the photographic process, in its negative/positive form, and this kind of structure where the negative would take the place of the machine language from the viewpoint of its reproducibility.

23. See David Alan Grier, "The Human Computer and the Birth of the Information Age," www.philsoc.org/2001Spring/2132transcript.html (last access March 14, 2010). See also David Alan Grier, When Computers Were Human, Princeton, Princeton University Press, 2005 . 
calculations and that is also directly based on the purchases of earlier often anonymous canvas works, the relationships point to the existence of a powerful and subtle intermedia-based historical model for contemporary art production. Such is the case with Rosika Desnoyers' needlegraphs. ${ }^{24}$

\section{PAINTING BY OTHER MEANS}

For the past 14 years, Rosika Desnoyers has been producing canvas-based pictures. Since the late 1990s, she has been working with existing needlepoints, the majority of which are of paintings, some by well-known artists (Chardin, Cezanne, Van Gogh, Millet). The production of a work begins with the purchase of a needlepoint produced by another anonymous amateur artist on eBay. Because of the nature of the eBay economy, the artifacts that Desnoyers purchases from dealers and private individuals have been, more often then not, stripped of their history.

When received, the needlepoint is subject to a detailed analysis of its physical condition. A condition report is produced which is accompanied by a graphic mapping out of its surface structure which takes account of each stitch. In this sense Desnoyers is reproducing the conditions of existence of an original pattern as well as mapping out an earlier program of work. But the objective of this examination lies elsewhere: to register the existence of errors, and other anomalies that can be treated as errors, which are defined as "any stitch that does not sustain the uniformity of the stitching." 25 Another chart is then produced that

24. Desnoyers' adoption of the word "needlegraphs" to describe her recent work is in reference to a book The Art of Needlegraph, published by Sylvia Goldman in 1974, where it refers to "counted stitchery: following a graph, box by box, to create a design." Sylvia Goldman, The Art of Needlegraph, Secaucus, Derby Books, 1974, np, quoted in Rosika Desnoyers, Archéologie et représentation d'erreurs dans la broderie populaire à petit point reproduisant des peintures de maîtres européens. Mémoire-création présenté comme exigence partielle de la maîtrise en arts visuels et médiatiques, Université du Québec à Montréal, août 2005, p. 32. For Desnoyers, "Needlegraph describes my practice of writing with a sewing needle and my exploration of the culture of representation of popular needlepoint." She continues: "Through a 'genealogical' practice, I propose a dialogue with the history of needlepoint in relation to contemporary cultural practice," p. 32. Much of the information on Desnoyer's practice that I am presenting in the following pages is drawn from her graduate thesis.

25. "The errors can include a stitch that does not cross diagonally over the support canvas, the result of inattention when stitching, as well as finer stitching like petit point, 
is used as a pattern for the production of a second needlepoint that duplicates the first in canvas size and number of stitches.

This second version is, however, monochrome and its surface is only broken by the presence of the errors noted in the original. Each error is registered by the absence of a stitch. The final work consists of the two needlepoints, an original and copy, which are considered to be "co-dependent." 26 There is therefore a consistent and rigorous logic to the production of the final work of art, that is composed of an "original" needlepoint "painting" with a well-defined, and often well-known subject matter, and a complementary work whose subject matter is the errors that have been isolated in the first work. Although different in terms of subject matter (one predominantly figurative and the other almost always abstract), the space that unites each of the binary elements of the final work is the "presence" of errors that have been transformed from negative to positive markers, from unproductive to productive graphic elements. The work is therefore the product of these errors as they have been noted and isolated, duplicated and registered in different spaces (graph paper and canvas). In a fundamental sense, it is the errors that become the ultimate "subject matter" of the final work. It is also the errors that serve as the bridge between the two needlepoints and, moreover, that become the determining component (the marks of difference) in the program through which the second work is produced.

There are therefore two facets to Desnoyers' engagement with the notion of a program as set out in a traditional Berlin work. The first consists of the original needlepoint which, it is important to note, is almost always the product of a massproduced pattern and therefore of an "original" (or preexisting) "program" of work. What is at stake in the original, from the viewpoint of the program, is precisely the space of operation, or the successful reproduction of a program of work and of creativity, a program that has itself been encoded in reproductive terms through the governing principles of the copy and of a rudimentary process of automation. However, what is also at stake, from a meta-creative viewpoint, is the presence of errors in the original. For they provide the excuse or the reason for the production of a second and unique canvas work which only becomes a possibility insofar as errors exist. (There is always the possibility that Desnoyers will purchase a perfect needlepoint, in which case it cannot be processed under the artist's criteria of analysis and system of reproduction.) What is also at stake

which adds to the level of detail by placing four stitches where there would otherwise only be one." Ibid., p. 38-39.

26. Ibid., p. 39. 


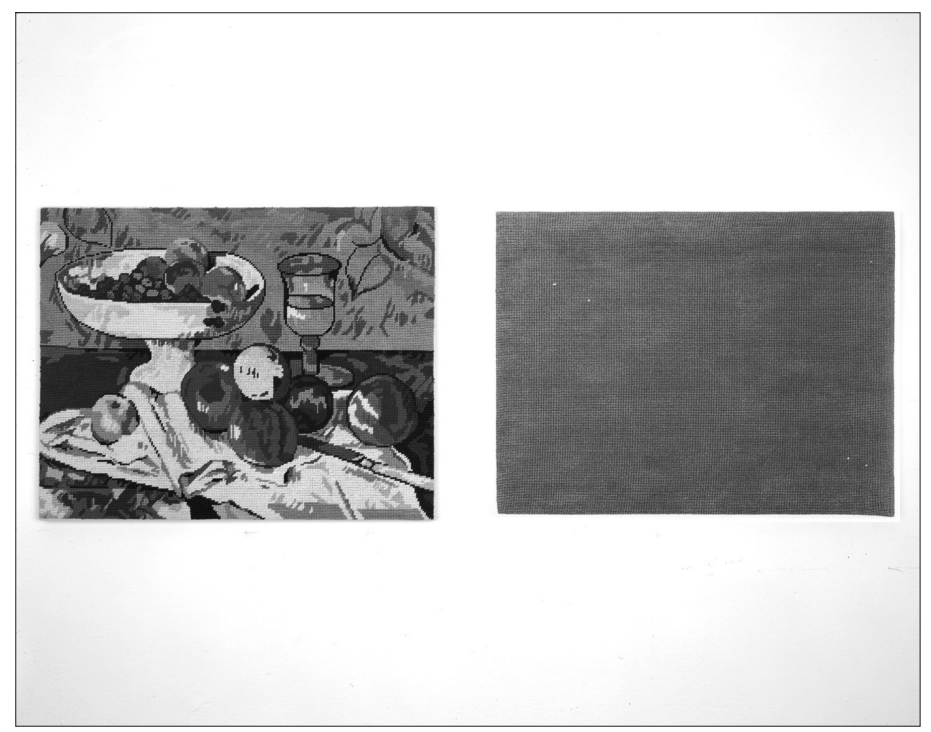

Fig. 1: Rosika Desnoyers, After Paul Cézanne, Still Life with Compotier (1879-1882), 2005-2006, Needlepoint, cotton on canvas, $51 \times 40,40$ and $50,80 \times 39,30 \mathrm{~cm}$, Private collection, Photo credit: Matthieu Brouillard.

in the second canvas work is the question of the efficacy of the founding principle upon which the original and meta-programs are based: the principle of the copy as applied to the mass production of pictures and the automation and democratization of creativity. The question of counting and errors, which is fundamental to the production and reproduction of a canvas work in Desnoyers' case, brings to mind the figure of the human computer who was so important in triggering Charles Babbage's quest to build a steam powered computing engine for producing error-free mathematical tables in the first quarter of the $19^{\text {th }}$ century. ${ }^{27}$ Desnoyers' practice resurrects the "space" of the computer's practice (the grid

27. See for example, Dionysius Lardner's comments on the presence of computational and typographic errors in various forms of mathematical tables in his article "Babbage's Calculating Engine," Edinburgh Review, $\mathrm{n}^{\circ}$ 59, July 1834, reprinted in Charles Babbage and his Calculating Engines: Selected Writings by Charles Babbage and Others, edited with an introduction by Philip Morrison and Emily Morrison, New York, Dover Publications, 1961, p. 163-224, p. 173-183. See also Babbage's 1822 letter to Sir Humphry Davy under the title "On the Application of Machinery to the Purpose of Calculating and Printing Mathematical tables," reprinted in Martin Campbell-Kelly (ed.), The Works of Charles Babbage, vol. 2, p. 6-14. 
system), maps its physical presence and its limits (defined in terms of human error) as well as its resonances across space, time, and history. But it only does so in an archaeological fashion inasmuch as this space is deployed between the two canvases and can only be understood to exist as a function of the grid systems and histories that underlie both canvases.

In addition to highlighting some interesting issues concerning the $19^{\text {th }}$ century relationship between programming, computing, automation and creativity, Desnoyers' practice engages with some important issues that have been raised in recent art. These include the role of academic style research, an increase in the exploitation of historical references in the conceptualization of artworks, the active use of the Web as an archival source for a work of art, and the appropriation of museum and conservation practices and their redeployment in the production of a new work of art. Other formal and methodological strategies resurface in her work under different-historical-conditions of existence. These include the use of the grid, the logic of the copy, the strategy of appropriation. Her work is also the result of an unusual-manual-articulation of the principle of automation such that its relationship to methods of mass-production is simultaneously highlighted and negated. These issues and strategies combine together to produce a final work that engages with, extends, and ultimately transforms the practice of painting into a meta-practice that can operate independently of its conventional foundation in the material medium of paint. A final consequence of Desnoyers' meta-practice is the way that it manages to embody without apparent contradiction some of the more programmatic aspects of late 1960 s conceptual art while simultaneously violating one of its most basic proposals: the negation of skill-based picture making practices that had traditionally served as a prerequisite for the production of art objects, or as a measure of their value.

\section{FROM IDEA AS PROGRAM TO THE PROGRAMMING OF AN IDEA}

In June 1967, Sol LeWitt published a seminal article in Artforum entitled "Paragraphs on Conceptual Art." ${ }^{28}$ In this article LeWitt outlined the parameters of a basic program of art production that was not based on craftsmanship as expressed through a mastery of specific forms of matter. Instead, LeWitt's definition outlined the characteristics of a work whose primary medium was ideas

28. Sol LeWitt, "Paragraphs on Conceptual Art," Artforum, vol. 5, $\mathrm{n}^{\circ}$ 10, Summer 1967 , p. 79-83, reprinted in Alicia Legg (ed.), Sol LeWitt, New York, The Museum of Modern Art, 1978, p. 166-167, p. 166. 
and that was produced in a strictly mechanical or automatic fashion once an idea was isolated with a view to its systemic development.

In conceptual art the idea or concept is the most important aspect of the work. When an artist uses a conceptual form of art, it means that all of the planning and decisions are made beforehand and the execution is a perfunctory affair. The idea becomes a machine that makes the art. This kind of art is not theoretical or illustrative of theories; it is intuitive, it is involved with all types of mental processes and it is purposeless. It is usually free from the dependence on the skill of the artist as a craftsman. It is the objective of the artist who is concerned with conceptual art to make his work mentally interesting to the spectator, and therefore usually he would want it to become emotionally dry. ${ }^{29}$

The programmatic nature of LeWitt's definition of conceptual art is clearly advanced in the statements "When an artist uses a conceptual form of art, it means that all of the planning and decisions are made beforehand and the execution is a perfunctory affair," and "The idea becomes a machine that makes the art." Thus LeWittian conceptual art was a preprogrammed form of art production that was based on the "idea" that an idea embodied its own logic of production and that its narrative potential could automatically unfold to achieve its full or total expression. The programmatic and automatic aspects of this form of conceptual art are clearly visible in LeWitt's work of the late 196os and 1970s, especially in his various modular variations on the cube. However, LeWitt's definition also highlights the intuitive and purposelessness of this type of work, thus separating it in principle, if not in fact, from the utilitarian objectives of more rational systems that might be designed for human use, as opposed to human contemplation and play.

Desnoyers' work process adheres to the programmatic aspects of LeWitt's 1967 definition of conceptual art in significant ways-systemic planning of work, automatic machine-like execution of work, emotional dryness-even if its relationship to the other components of his definition are more ambiguous. For example, LeWitt defiantly separated conceptual art from the more traditional art of painting. In his words, "Art that is meant for the sensation of the eye primarily would be called perceptual rather than conceptual. This would include most optical, kinetic, light, and color art." ${ }^{30}$ Desnoyers' practice is, in contrast, resolutely engaged with a specific and highly programmed form of painting (canvas work) 
and she is also engaged with the question of colour both in terms of an original hand-made product and in terms of a reproduction that is unique.

Desnoyers' engagement is also narrowly focused on the presence of errors and their identical spatial relations across two canvas works. Thus her work is founded on the idea of the successful application of a program of work that is doubly articulated. However, her focus on errors strips both painting and colour of their purely retinal significance as key indicators of a person's creative autonomy and, therefore, as primary components in the craft-based measure of an artist's originality. Creativity is, in contrast, located in the identification of an error that highlights, in an irrational manner and through an intuitive presence made visible, the canvas worker's individuality and therefore her/his ability to generate marks of significant difference. This inversion in Berlin work's logic and its promise of a "perfect" reproduction is based on the fact that the errors can be considered to be signs of failure within a craft-based system of mass production that is subject to the pressures of creative homogenization. (It being understood of course that, if in principle this might be the case, the process of creation nevertheless always remains in the hands of the embroiderer and therefore is always subject-like the human computer-to human error). LeWittian conceptual methodology is therefore adhered to in its unconventional-purposeless and intuitive-articulation of rationalist strategies of automatic production because the errors are systemically uncovered and systemically reproduced in Desnoyers canvas works. In other words, she has chosen to follow another "system" and another program of work as opposed to the correct and authorized one.

However, at the end of this process of liberating and relocating the markers of creativity, the idea of painting/colour as interlocked chromatic stimulus and marker of difference remains intact. But it only operates in this way in the second error-based reproduction that is the meta-product of a meta-program. For the production of a second canvas work sidelines (but does not negate) the retinal dimension of the first in favour of a program-based conceptual engagement with a series of absences (or errors) that have served as the generators of an original and unique canvas work. This displacement opens the way to a doubling of the idea of a program and by extension of a programmed approach to painting. The doubling creates a space between the two where the errors in the second canvas work function to confirm the common identity of the two works which can only be defined in terms of their "co-presence." This identity can only be grasped intellectually as an idea-the idea of co-presence guaranteed by the negative/positive duplication of errors-as defined by two identical sets of absences (errors in the first, conventional subject matter in the second). In other 
words, the final work can only be coherently explained through the presence of the errors (now positive markers) that guarantee its identity as art work through their co-presence in two distinct locations where they function simultaneously as negative and positive signs of the mastery of a program of work and its model of creativity.

The error becomes a stigma in one case, and a generator in the other case. It signifies imperfection and failure in the first case and the fulfillment of an unfulfilled potential and thus the locus of possibility in the second case. In the former case, it points to a failure in one's ability to master a craft and a simple task, and in the latter case, it involves a mastery of a failure and of a contingent possibility as well as the potential concentrated in a local "point of departure," etc. Paraphrasing LeWitt, one might declare that "The idea [of the error] becomes a machine that makes the art." However, there is still more to uncover in this method. LeWitt also pointed out that "This kind of art is not theoretical or illustrative of theories; it is intuitive, it is involved with all types of mental processes and it is purposeless." A similar attitude can be detected in Desnoyers' practice since it is based on the acknowledgement of the positiveintuitive-value of unforeseen errors. But these "useless" elements, the product of lapses of concentration or deviations in a practice, have been reappropriated and their historical and theoretical values are also openly acknowledged. The graph-like net that Desnoyers reports over an original needlepoint has opened the door to a history that is also shared by LeWitt's modular cubes (even though they are formed of permutations of three-dimensional squares). But this history extends beyond them into the distant and immediate past (origins of Berlin work, women's $19^{\text {th }}$ century domestic picture making practices, and conceptual art, feminist art and media practices). Although both approaches are rooted in a simple logic that unfolds in an apparently automatic way once it has been activated, their ultimate art historical values are differentially inflected because of their contents and labour matrices; and in the process, a particular brand of conceptual art is extended beyond its original parameters and history.

One can describe the linkage between identity, idea and conceptual art in Desnoyers' work in another way that sheds further light on the direction and significance of this extension in LeWitt's late 1960 s brand of conceptual art. The initial articulation of a "program" has to do with the production of an original needlepoint by an anonymous person on the basis (one assumes) of a printed pattern that had served as the program of work to follow in its production. The final work stands in for the successful execution and completion of that program. The second program is based on a reprogramming of the first in terms of 
stitching errors and their use for the production of a second needlepoint. The second work therefore stands in for the successful execution of that program. Both canvas works, the products of similar yet different programs, constitute the final work in which the idea of painting has been programmed and also reprogrammed beyond its material basis (paint) but not beyond its support system. In fact, the support system served as the logical basis (grid system), machine code, and program for its extension. While the errors in the first point to a particular program's failures (or more accurately to an individual "computer's" errors and thus to an all too human presence), their presence in the second transforms the failure into the key elements in the successful execution of a second and identical program (in the sense that its subject matter is the errors that are integral, if anomalous, elements of the original picture). ${ }^{31}$ This process can be continued indefinitely as long as there are errors to discover. ${ }^{32}$ This brings us back to another of LeWitt's statements concerning conceptual art's methodology:

To work with a plan that is preset is one way of avoiding subjectivity. It also obviates the necessity of designing each work in turn. The plan would design the work. Some plans would require millions of variations, and some a limited number, but both are finite. Other plans imply infinity. In each case, however, the artist would select the basic form and rules that would govern the solution of the problem. After that the fewer decisions made in the course of completing the work, the better. This eliminates the arbitrary, the capricious, and the subjective as much as possible. This is the reason for using this method. ${ }^{33}$

Desnoyers' programmed approach to painting (if one can now formulate it in this way) adheres to LeWitt's late 196os understanding of the planned nature of systems-based conceptual art and its basic method of operation in a rigorous fashion. However, her focus on errors highlights not only their arbitrary, capricious and subjective origins, but also their systemic, programmatic and conceptual potential. This focus is, of course, also supported by LeWitt's intuitive and anti-rational definition of conceptual art, and yet it is through this positive

31. This reminds one of another positive conclusion to a history of (mathematical) errors with Charles Babbage's development of his Difference Engine which was conceived as a solution to the problem of the errors produced in mathematical tables by human computers. See Martin Campbell-Kelly, "Charles Babbage's Table of Logarithms (1827)," Annals of the History of Computing, vol. 10, $\mathrm{n}^{\circ}$ 3, July 1988, p. 159-169.

32. Note that the second canvas work also has references to a history of painting, in this case to a history of monochrome painting, which is a more recent and radical solution to the problem of painting in an age of mechanical-automatic-reproduction.

33. LeWitt, 1967. 
re-articulation of errors that Desnoyers is also able to undermine one of the key sentences of LeWitt's influential 1969 "Sentences on Conceptual Art." Sentence number 8 reads as follows: "When words such as painting and sculpture are used, they connote a whole tradition and imply a consequent acceptance of this tradition, thus placing limitations on the artist who would be reluctant to make art that goes beyond the limitations." ${ }^{34}$ Note the subtle distinction LeWitt uses to nuance his discussion of limits: "When words such as painting and sculpture are used..." (my emphasis). In an important sense, the question of distinctions and limits revolves around words and their use. This includes, of course, how one uses words like program and automatic. For they circumscribe meaning and, in doing so, they delimit what can be and what cannot be included in a word's use. But they can also be subject to the vicissitudes of use over time. Hence the importance of etymology, the study of a word's evolution over time as defined by the shifting boundaries of its everyday use. A case in point is the history of the word pixel. ${ }^{35}$ Thus it is in terms of the question of limits and a LeWittian version of conceptual art that one can appreciate the basic singularity of Desnoyers' practice, which resides in its capacity to produce a painting-the same idea of a painting (one that is based on errors) in a potentially endless fashion-by way of a displacement in its programmed process of production, such that it exists beyond its traditional limits as defined in its primary raw material: paint.

One can perhaps argue, in response, that the original needlepoints that Desnoyers uses in her work also function in this way. However, this is not, in fact, strictly true. The originals function in relation to their own world which is rooted in a domestic space and is governed by the history of embroidery and a history of appropriate needlepoint subject matter that includes paintings but also a whole range of other subjects. Desnoyers' work functions, in contrast, in relation to art history and it is firmly rooted in the world of contemporary art in terms of the interfaces it creates between feminism (understood in terms of the resurrection

34. LeWitt, 1969, p. 11. Compare this approach to Chuck Close's comments in relation to his low resolution painting method in order to fully appreciate the radical nature of Desnoyers' extended paintings: "I wanted to make a painting in which every square inch was made the same way." Robert Storr, "Interview with Chuck Close," Chuck Close, New York, Museum of Modern Art, 1998, p. 88-89, quoted in Richard Shiff, "Allover You," Artforum, vol. 36, n 8, April 1998, p. 95. While Close's approach fails to qualify as a form of conceptual art, Desnoyers' does. For a further discussion of Close's work in relation to his use of a grid system and to the contemporary issue of the analogue versus digital image, see Shiff, 1998, p. 95, 97-98, 135.

35. See Lyon, "A Brief History of 'Pixel."” 
of the anonymous, local history of a woman's creativity and work), the history of the grid, the monochrome, the found object, serial systems, and conceptual art, etc. ${ }^{36}$ If her primary reference is still painting (and her choice of art historical subject matter reinforces the primacy of this reference), then it is also important to point out that the web of references covered and uncovered by her work breaches the boundaries of art history and contemporary art on a number of fronts. It reaches out, as I have demonstrated, well beyond painting's disciplinary boundaries, while nevertheless remaining intimately tied to it through its primary subject matter and support system.

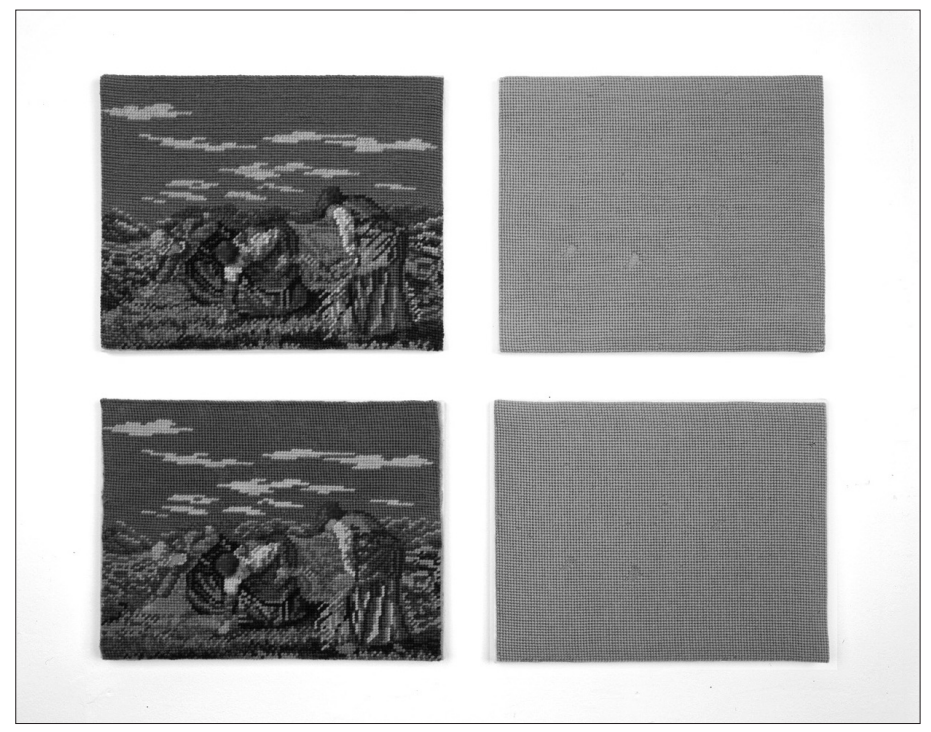

Fig.2: Millet grid: Rosika Desnoyers, After Jean-François Millet, Gleaners (1857), 2002-2003, Needlepoint, wool on canvas, 30,50 x 24,70 and 29,30 x 24,70 cm, and After Jean-François Millet, Gleaners (1857), 2006, Needlepoint, wool on canvas, 30,70 x 23,90 and 29,90 x 23,80 cm, Private collection, Photo credit: Matthieu Brouillard.

36. On the use of the grid in modern and contemporary art see Rosalind E. Krauss, “Grids," October 9, Summer 1979, p. 50-64. Krauss' argument about the dualist narrative/ symbolic and anti-narrative/structured/structural nature and $19^{\text {th }}$ century roots of the grid in physiological optics sheds additional light on Desnoyers' practice. While her practice is not symbolic in its narrative engagement with the grid, her work does engage with another and perhaps more fundamental grid-like matrix since it is in a "programmatic" dialogue with the weave of the canvas, the history of women's embroidery practices, computing technologies, and conceptual art. 


\section{CONCEPTUAL ART AS A PROGRAMMED WEB OF HISTORICAL ASSOCIATIONS}

Desnoyers' first needlepoint pictures were inspired by prints produced by Mary Cassatt which she translated into flat patterns of colour whose limits were determined by the original contours of the subjects represented. ${ }^{37}$ These slightly more abstract images were repeated horizontally in order to produce a quasi-cinematic image and also to underline the reproducibility inherent to the print medium.

The works articulate a sociologically inspired filiation between the history of a specific medium - embroidery-and the history of practices of art associated with women artists. By choosing, or more accurately re-appropriating prints by Mary Cassatt, these works link private/public historical spaces (Cassatt's late $19^{\text {th }}$ century depictions of intimate relationships between women) to other private/public ones (the pictorial articulation of references to the history of a domestically practiced picture making activity, in this case needlepoint, as well as the history of a category of subject matter explored by amateur embroiderers whose traces are preserved in needlepoint reproductions of canonical paintings). This articulation produces, in Desnoyers' words, visual works that exhibit a “... reflexively embedded in an awareness of the history of Berlin work and needlepoint as a technique and as a practice that is complexly positioned within social and aesthetic relations." ${ }^{38}$

However, Desnoyers' two Cassatt-based works also go beyond the art historical and sociological dimensions of women's art practices by evoking more than one medium and the common logic underwriting different practices and products. They not only refer back to original prints and their subject matters, the early $19^{\text {th }}$ century history of Berlin work and the kinds of programs used in weaving and embroidery at that time, they also refer to a range of media used in contemporary art production whose subject matter includes, most significantly, the history and aesthetics of each medium. These include contemporary feminist embroidery practices, but they also embrace film and serial painting. In addition, they clearly raise questions about the distinction between analogue (or continuous) and digital (or discontinuous) modes of reproduction through their references and their surface characteristics that echo their dialectical continuous/discontinuous mode of production (movement of the needle through the canvas grid system from bottom to top) and their discontinuous or "pixilated" mode of presentation. The initial questions raised in these early works have been

37. The two prints were Mary Cassatt's Gathering Fruit (1895) and In the Omnibus (1890-1891).

38. Rosika Desnoyers, 2005, p. 32. 


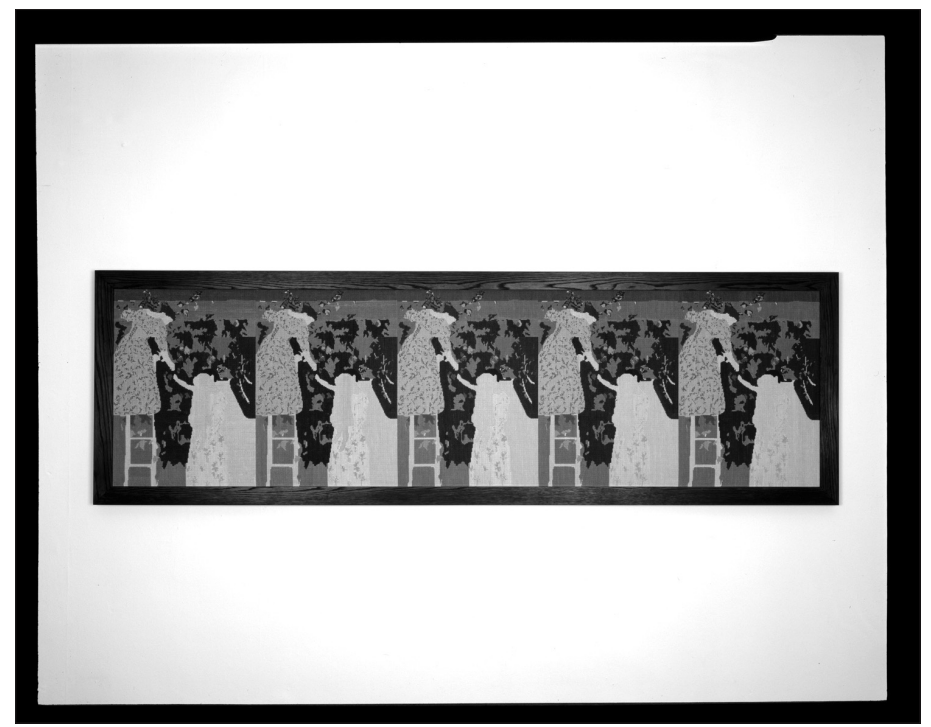

Fig.3: Rosika Desnoyers, After Mary Cassatt, Gathering Fruit (1893), 1994, Needlepoint, cotton on canvas, 203 x $62 \mathrm{~cm}$, Private collection, Photo credit: Matthieu Brouillard.

explored in her later binary works where she uses existing needlepoint works to produce new monochromes whose threshold of representation are subject to the dictates of an archeology of errors.

Desnoyers' process of production is therefore of particular interest when considered in terms of the rudimentary programming languages (squares,grids and holes) and the programs of work associated with Berlin work and the Jacquard loom. These are the kinds of programs and programs of work that are built into "counted stitchery: following a graph, box by box, to create a design." It is also through these similar, yet rudimentary concepts of programming-these early and basic threshold programs between the human and machine worlds-that one can begin to appreciate the central logic in terms of which any work is able to serve as a powerful media historical matrix that functions to promote new forms of non-perceptual, anti-retinal art. While a graph or pattern serves as a program for the production of a design in the case of a conventional needlepoint work, the creation of errors and the graph that is used to locate their position in a given design serves as a meta-program for the production of a new work of art. The errors serve therefore as an interface between two systems defined in terms of two distinct yet interconnected graphs The fact that this interface can be clearly identified with the "exact" spatial deployment of one or more errors in two "autonomous" needlepoint works is, as we have seen, particularly important 
and significant. This type of interface allows one work to "replace" the other (as opposed to mirroring the other) in a relationship of co-existence. But it also does much more, for it effectively reprograms, as I have suggested, a particular yet potentially infinitely reproducible retinal-based needlepoint painting into a quasiretinal research- and canvas-based conceptual work of art. The original work is the product of one system of art. This system is related to the amateur craft-based artist and her/his use of a mass-produced chart or template. The second and final work is defined in terms of a doubly articulated structure that allows it to exist, through a web of logical connections and associations, in multiple media historical, sociological and art historical spaces. As such it prompts one to question what should be included in a history of new media. Should it only include works based on innovations in hardware and (from the viewpoint of the media arts) novel aesthetic propositions based on new forms of hardware and software, or does one also include innovations in the application of different systems of logic to both traditional and non-traditional media? Finally, what happens to a history of media when the innovative power of a logical system is defined in terms of a generic program as in the case of a grid system and its basic element (the square) as opposed to the products of that system? These questions suggest that there might be a number of important reasons why one should reserve a place for needlepoint paintings - and, by extension, for Desnoyers' meta-practice-in a history of programming languages and vice versa. 